\title{
Patient satisfaction concerning implant-supported prostheses: an observational study
}

\section{Bruno César de Vasconcelos GURGEL}

Ana Luísa de Barros PASCOAL Bruno Luiz Menezes de SOUZA Poliana Medeiros Cunha DANTAS Sheyla Christinne Lira MONTENEGRO

Angelo Giuseppe Roncalli da Costa OLIVEIRA

Patrícia dos Santos CALDERON

Universidade Federal do Rio Grande do Norte - UFRN, Department of Dentistry, Natal, RN, Brazil.

Declaration of Interests: The authors certify that they have no commercial or associative interest that represents a conflict of interest in connection with the manuscript.

Corresponding Author:

Bruno César de Vasconcelos Gurgel

E-mail: bcgurgel@yahoo.com.br

DOI: 10.1590/1807-3107BOR-2015.vol29.0034

Submitted: May 03, 2014

Accepted for publication: Nov 02, 2014

Last revision: Jan 06, 2015
Abstract: The aim of this observational study was to assess the degree of patient satisfaction toward implant-supported prostheses. A questionnaire was used with two scales (one consisting of detailed adjectival and the other of numerical responses) regarding chewing, esthetics, speaking, comfort and overall satisfaction. The scales were administered to a sample of 147 patients treated with implants and prostheses. The data were submitted to the Kappa statistic and the Chi-square test to analyze the association between dependent and independent variables. High degrees of satisfaction (greater than 91\%) were found for all categories evaluated, regardless of gender, age, number of implants or type of prosthesis. "Comfort" was associated significantly with the number of implants $(p=0.038)$, and "speaking" was associated significantly with the type of prosthesis $(p=0.029)$. Positive agreement was found between the scales for all categories evaluated, without statistically significant differences regarding respondent preference $(p=0.735)$. Patients treated with implant-supported prostheses were highly satisfied with the treatment.

Keywords: Personal Satisfaction; Dental Implants; Dental Prosthesis, Implant-Supported.

\section{Introduction}

The high success rate of treatment involving implant-supported prostheses is based on different parameters, the most common of which is clinical. However, results based on patient satisfaction are an important aspect in determining treatment success. ${ }^{1,2}$ Most studies evaluating the satisfaction of completely edentulous individuals generally compare conventional full dentures to implant-supported prostheses, and report a greater degree of patient satisfaction with the latter. $3,4,5,6,7,8$ Other studies also report high degrees of satisfaction among patients with overdentures, regardless of the type of support. ${ }^{1,9,10,11,12,13,14,15}$

Several reports on the satisfaction of partially-edentulous patients treated with dental implants address single prosthetic rehabilitation and generally report high degrees of satisfaction. ${ }^{1,2,16,17}$ Studies assessing the satisfaction of patients treated with other implant-supported partial dentures ${ }^{1,18}$ are needed to provide better information on outcomes related to this type of treatment. 
Thus, the aim of the present study was to determine the degree of satisfaction of patients treated with implant-supported prostheses, and the association with demographic variables (gender and age), number of implants and type of prosthesis. The general hypothesis is that these factors could influence the satisfaction level.

\section{Methodology}

A cross-sectional study was carried out involving patients treated with implant-supported prostheses at a university dental department between 2000 and 2010. This study received the approval of the local Human Research Ethics Committee (process no. 186/10-P).

A sample size calculation was performed to determine the minimum necessary sample size from a universe of 350 patients treated with implant-supported prostheses. The minimum sample size was 145 patients, based on an $80 \%$ prevalence rate of a high degree of overall patient satisfaction, with a $95 \%$ confidence interval, a 93.8\% test power and $5 \%$ level of significance.

Patient selection was carried out following previous evaluation of the records of individuals subjected to implant-supported prostheses. The inclusion criteria were patients with implants seen at the dental department between 2000 and 2010 and wearing implant-supported prostheses for at least six months. Patients fulfilling the inclusion criteria were contacted and asked to come to the department to answer the questionnaire. All subjects were informed about the objectives and characteristics of the study, both verbally and in writing. Those who agreed to participate signed a statement of informed consent prior to the administration of the questionnaire.

A questionnaire was administered with five items on how the individuals assessed their satisfaction in regard to chewing, esthetics, speech, comfort and overall satisfaction, using two response scales: a numerical scale ranging from 0 to 10 (adapted from a pain scale $)^{19}$ and an adjectival scale to qualify subjective perception of the patient (highly satisfied, satisfied, partially satisfied, not satisfied, not at all satisfied; adapted from Pjetursson $e t$ al. .) ${ }^{2}$ The participants were informed of the meaning of each category prior to selecting their responses according to the each scale. ${ }^{9}$ The questionnaire consisted of the following questions:
1. How would you evaluate your ability to chew foods?

2. Are you satisfied with the appearance of your prosthesis?

3. How would you evaluate the comfort of your implant-supported prosthesis?

4. How would you evaluate your speaking ability with your implant-supported prosthesis?

5. How would you evaluate your overall satisfaction with the outcome of your treatment?

Agreement between the scales was evaluated by categorizing the numerical scale ("0-2"; "3-4"; “5-6"; "7-8" and "9-10") and relating it to the adjectival scale (five-grade categorizing scale). The data were submitted to statistical tests (descriptive and inferential analyses) with the aid of the SPSS 20.0 software application (Statistical Package for the Social Sciences, free version, IBM, New York, USA). Evaluation of the between-scale agreement was carried out using the Kappa (K) test. The Chi-square test was used to determine associations between the categorical variables, using contingency tables. Individual preference for one scale over the other was also evaluated using the Chi-square test.

To assess the association between the dependent variable (satisfaction level) and the explanatory variables (gender, age, number of implants and type of prosthesis), taking into account that all variables are categorical, a bivariate analysis was performed using the Chi-square test with a significance level of $5 \%$.

\section{Results}

The sample was composed of 31 men (21.1\%) and 116 women $(78.9 \%)$ with a mean age of 53.6 years (standard deviation: 12.29 years; range: 18 to 80 years). The overall sample had a total number of 487 implants. Among the types of prostheses, 11 (7.5\%) were fixed dentures, 70 (47.6\%) were single crowns, 41 (27.9\%) were fixed partial dentures and $25(17 \%)$ were overdentures. Moreover, 138 prostheses (93.9\%) were permanent and $9(6.1 \%)$ were temporary.

There was no missing data in the analysis. The K statistic revealed moderate agreement in all categories analyzed (chewing function: $\mathrm{K}=0.520$; comfort: $\mathrm{K}=0.387$; speaking: $K=0.300$; esthetics: $K=0.509$; and overall satisfaction: $K=0.469$ ). It was decided that the data obtained from the numerical scale would be used 
because of the concordance between the scales. It was also decided that, because of the homogeneity in the distribution of the responses, the scale values should be re-categorized in order to extract the best information from the data generated (up to score 9 and score 10).

Table 1 shows the results of the Chi-square test. No statistically significant associations in regard to the items for "chewing function," "esthetics" and "overall satisfaction," were found for age, gender, number of implants or type of prosthesis $(p>0.05)$.

"Comfort" was significantly associated with the number of implants $(p=0.038)$. The maximum satisfaction score was obtained from $61.1 \%$ of the patients with only one implant, $50.6 \%$ of those with two to four implants and $30 \%$ of those with five to thirteen implants.

"Speaking" was significantly associated with the type of prosthesis $(p=0.029)$. The maximum satisfaction score was obtained from $87.8 \%$ of the patients with fixed partial dentures, $75.7 \%$ of those with single crowns, $60 \%$ of those with overdentures and $54.5 \%$ of those with fixed dentures.

Regarding individual preference for one scale over the other, $50.3 \%$ preferred the numerical scale and $49.7 \%$ preferred the adjectival scale. This difference yielded no statistical significance $(p=0.735)$.

\section{Discussion}

The theory of dental implants and treatment success in oral rehabilitation are well documented in the literature. Studies on dental implants generally focus on their success and failure from a biological standpoint, whereas few investigations have been carried out on patient satisfaction according to treatment results. ${ }^{20}$ The degree of patient satisfaction is the result of a complex interrelationship between psychosocial and physiological factors. ${ }^{10,11,12,21,22,23}$ In the present study, patient satisfaction with implant-supported prostheses was assessed based on chewing function, speaking, esthetics, comfort and overall satisfaction using two different scales. The findings showed a greater than $91 \%$ satisfaction rate. Previous studies have made a similar evaluation using a variety of questionnaires and scales. $1,2,3,5,8,11,21,22,23$

In the present study, high levels of patient satisfaction were found, with no statistically significant difference between genders, which is in agreement with findings described in the literature. ${ }^{5,9,21,22}$ Evaluating patients with mandibular overdentures, Pan et al. ${ }^{22}$ found no statistically significant differences between genders, in regard to comfort, speaking or esthetics. In another study involving patients with mandibular overdentures, Siadat et al. ${ }^{9}$ found that men had greater expectations regarding comfort and were more satisfied with esthetics; however, the gender differences were non-significant. Balaguer et al..$^{21}$ analyzed patients with maxillary and mandibular overdentures, in regard to speaking, esthetics, overall satisfaction and chewing function, and found a statistically significant gender difference only regarding the chewing function, for which men were more satisfied. According to Steele et al., ${ }^{23}$ male individuals are less concerned about dental loss and different aspects of rehabilitation options than females.

No statistically significant association was found between age and degree of satisfaction, which is in agreement with findings described in the literature.,21 However, despite the lack of statistical significance, a greater degree of satisfaction was found among adult patients. Maximum satisfaction scores were recorded for $65.3 \%$ of individuals between 18 and 48 years of age, whereas the satisfaction scores among individuals from 49 to 59 and from 60 to 80 years were $52.9 \%$ and $46.8 \%$, respectively. Moreover, the number of implants increased with age, and a reduction in satisfaction regarding comfort occurred with the increase in number of implants.

Although the literature does not report any association between the degree of patient satisfaction and the number of implants, ${ }^{21,24}$ a statistically significant association was found in the present study involving comfort and number of implants. The participants reported hygiene difficulties, particularly in cases of fixed and removable dentures and fixed partial dentures. A similar finding was described in a systematic review of the literature carried out by Strassburger et al. ${ }^{25}$ who reported that patients tend to have greater hygiene difficulties with these types of prostheses. Moreover, it has been reported that an increase in the number of implants implies greater hygiene difficulty, in comparison with the natural dentition ${ }^{18}$ and conventional dentures. ${ }^{26}$

The protocol for full denture fixation used to be six implants in both the mandible and maxillary; it 


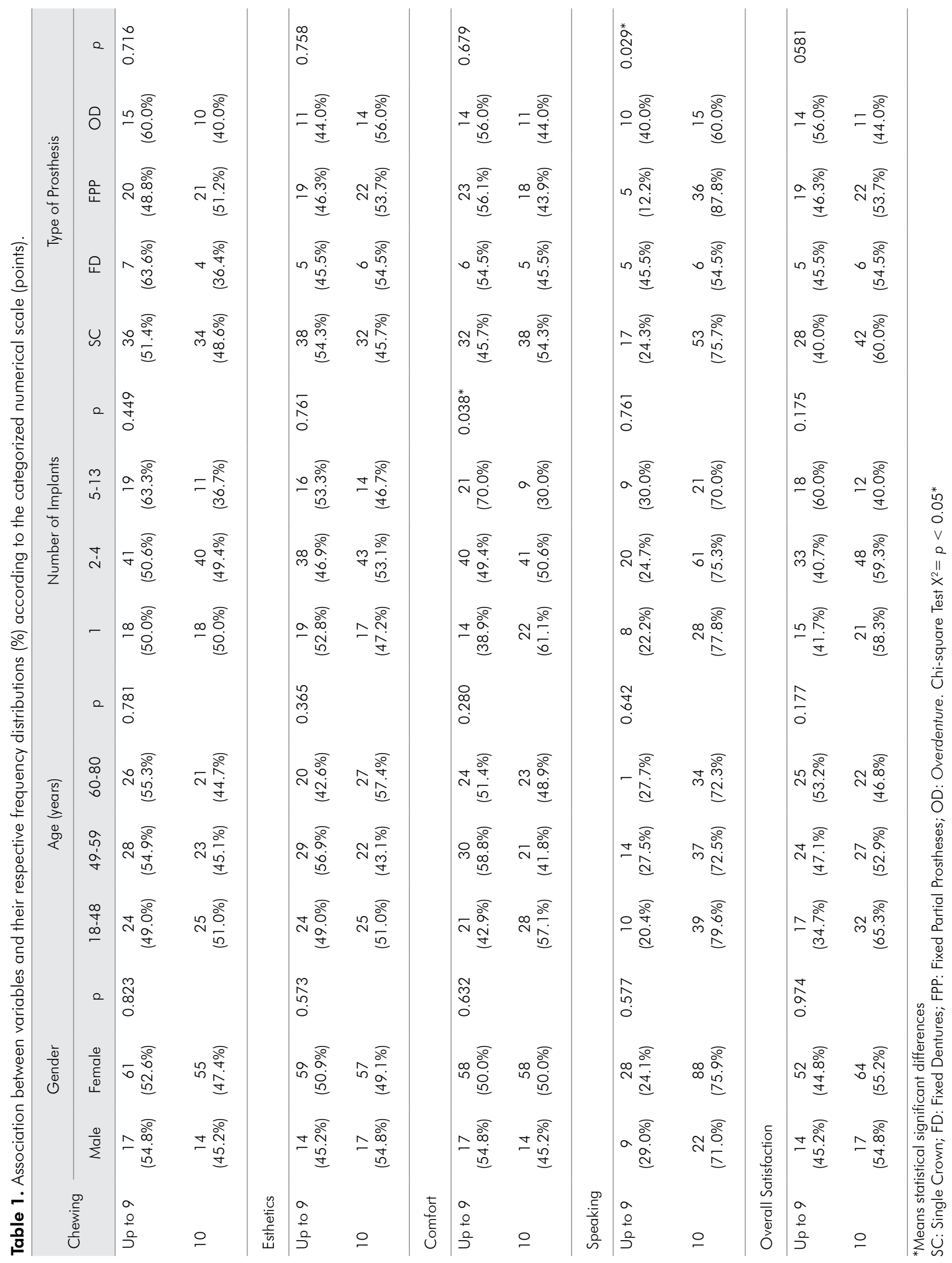


has changed to six implants in the maxilla and five in the mandible. This is currently considered the safe treatment method. In 2011, Maló et al. ${ }^{27}$ published a study involving a ten-year follow-up of patients treated with the "all-on-four" system, consisting of acrylic full dentures fixed on four well-distributed implants in the maxilla. They concluded that the technique is viable in the long term for mandibular dentures. The satisfactory results achieved after changes were made in the pre-established protocols show that it is possible to reduce the number of implants and still have functional prostheses, resulting in a reduction in cost and greater patient satisfaction, especially in regard to hygiene.

Another statistically significant association was found between the type of prosthesis and patient satisfaction in regard to speaking. Lower degrees of satisfaction were found among edentulous patients treated with fixed and removable dentures, in comparison with other types of prostheses. According to Jacobs et al., ${ }^{28}$ complete edentulism can affect speech performance. This finding may be explained by the removal of the periodontal ligament (responsible for proprioception), which has repercussions related to speech. In contrast, partially edentulous patients still have a sufficient number of teeth to maintain satisfactory speech performance. ${ }^{28,29}$ A number of studies report high degrees of satisfaction among completely edentulous patients with implant-supported prostheses. . $^{1,2,11,14,21}$ However, further studies are needed to make a better assessment of patients with single crowns and fixed partial implant-supported prostheses.

As for patient satisfaction in regard to the assessment tools, Pjetursson et al. ${ }^{2}$ compared a questionnaire with a numerical scale (Visual Analog Scale) and with a detailed adjectival scale, and found a positive correlation between the two methods. In the present study, a similar result was found, indicating that both evaluation scales may be used in determining satisfaction, and that patient preference should be considered. The limitation of this observational study was that there was no control group and randomization was not possible. This can create bias and lead to difficult cause-effect relationships. ${ }^{30}$ However, it was a cross-sectional study within a specific population, without any intention of establishing a generalization for the whole population. Therefore, further studies that replicate the results in different populations, places, and time periods are needed.

Thus, the success of implant-supported prosthetic rehabilitation should not be judged based solely on clinical parameters. Patient satisfaction is one of the most important goals in achieving oral rehabilitation. Although subjective, this aspect is considered an essential indicator of treatment success and a parameter for the quality control of prosthetic procedures. ${ }^{1}$

\section{Conclusion}

Considering the sample analyzed and the method applied, it can be concluded that patients treated with implant-supported prostheses were highly satisfied with the treatment. Additionally, it could be observed that "Comfort" and "Speaking" were significantly associated with the number of implants and type of prosthesis, respectively.

\section{References}

1. Baracat LF, Teixeira AM, Santos MBF, Cunha VP, Marchini L. Patients' expectations before and evaluation after dental implant therapy. Clin Implant Dent Relat Res. 2011 Jun;13(2):141-5.

2. Pjetursson BE, Karoussis I, Bürgin W, Brägger U, Lang NP. Patients' satisfaction following implant therapy. A 10-year prospective cohort study. Clin Oral Implants Res. 2005 Apr;16(2):185-93.
3. Assunção WG, Zardo GG, Delben JA, Barão VA. Comparing the efficacy of mandibular implant-retained overdentures and conventional dentures among elderly edentulous patients: satisfaction and quality of life. Gerodontology. 2007 Dec;24(4):235-8.

4. Cune MS, de Putter C, Hoogstraten J. Treatment outcome with implant-retained overdentures: part II - patient satisfaction and predictability of subjective treatment outcome. J Prosthet Dent. 1994 Aug;72(2):152-8. 
5. Awad MA, Lund JP, Dufresne E, Feine JS. Comparing the efficacy of mandibular implant-retained overdentures and conventional dentures among middle-aged edentulous patients: satisfaction and functional assessment. Int J Prosthodont. 2003 Mar-Apr;16(2):117-22.

6. Awad MA, Lund JP, Shapiro SH, Locker D, Klemetti E, Chehade A, et al. Oral health status and treatment satisfaction with mandibular implant overdentures and conventional dentures: a randomized clinical trial in a senior population. Int J Prosthodont. 2003 Jul-Aug;16(4):390-6.

7. Meijer HJ, Raghoebar GM, Van't Hof MA, Geertman ME, Van Oort RP. Implant-retained mandibular overdentures compared with complete dentures: a 5-years' follow-up study of clinical aspects and patient satisfaction. Clin Oral Implants Res. 1999 Jun;10(3):238-44.

8. Ellis JS, Elfeky AF, Moynihan PJ, Seal C, Hyland RM, Thomason $M$. The impact of dietary advice on edentulous adults' denture satisfaction and oral health-related quality of life 6 months after intervention. Clin Oral Implants Res. 2010 Apr 1;21(4):386-91.

9. Siadat H, Alikhasi M, Mirfazaelian A, Geramipanah F, Zaery F. Patient satisfaction with implant-retained mandibular overdentures: a retrospective study. Clin Implant Dent Relat Res. 2008 May;10(2):93-8.

10. Meijer HJ, Batenburg RHK, Raghoebar GM. Influence of patient age on the success rate of dental implants supporting an overdenture in an edentulous mandible: a 3-year prospective study. Int J Oral Maxillofac Implants. 2001 JulAug;16(4):522-6.

11. Al-Zubeidi MI, Alsabeeha NHM, Thomson WM, Payne AG. Patient satisfaction and dissatisfaction with mandibular two-implant overdentures using different attachment systems: 5-year outcomes. Clin Implant Dent Relat Res. 2012 Oct;14(5):696-707.

12. Emami E, Heydecke G, Rompré PH, de Grandmont P, Feine JS. Impact of implant-support for mandibular dentures on satisfaction, oral and general health-related quality of life: a meta-analysis of randomized-controlled trials. Clin Oral Implants Res. 2009 Jun;20(6):533-44.

13. Kaptein ML, Hoogstraten J, de Putter C, de Lange GL, Blijdorp PA. Dental implants in the atrophic maxilla: measurements of patients' satisfaction and treatment experience. Clin Oral Implants Res. 1998 Oct;9(5):321-6.

14. Quirynen M, Alsaadi G, Pauwels M, Haffajee A, van Steenberghe D, Naert I. Microbiological and clinical outcomes and patient satisfaction for two treatment options in the edentulous lower jaw after 10 years of function. Clin Oral Implants Res. 2005 Jun;16(3):277-87.

15. Sandberg G, Stenberg T, Wikblad K. Ten years of patients' experiences with fixed implant-supported prostheses. J Dent Hyg. 2000 Fall;74(4):308-16.

16. den Hartog L, Slater JJ, Vissink A, Meijer HJ, Raghoebar GM. Treatment outcome of immediate, early and conventional single-tooth implants in the aesthetic zone: a systematic review to survival, bone level, soft-tissue, aesthetics and patient satisfaction. J Clin Periodontol. 2008 Dec;35(12):1073-86.

17. Vermylen K, Collaert B, Lindén U, Björn AL, De Bruyn H. Patient satisfaction and quality of single tooth restorations. Clin Oral Implants Res. 2003 Feb;14(1):119-24.

18. Yi SW, Carlsson GE, Ericsson I, Kim CK. Patient evaluation of treatment with fixed implant-supported partial dentures. J Oral Rehabil. 2001 Nov;28(11):998-1002.

19. Calderon PS, Peixoto RF, Gomes VM, Corrêa ASM, Alencar EN, Rossetti LM, et al. Concordance among different pain scales in patients with dental pain. J Orofac Pain. 2012 Spring;26(2):126-31.

20. Carr AB. Successful long-term treatment outcomes in the field of osseointegrated implants: prosthodontic determinants. Int J Prosthodont. 1998 Sep-Oct;11(5):502-12.

21. Balaguer J, García B, Peñarrocha MA, Peñarrocha M. Satisfaction of patients fitted with implant-retained overdentures. Med Oral Patol Oral Cir Bucal. 2011 Mar 1;16(2):204-9.

22. Pan S, Awad M, Thomason JM, Dufresne E, Kobayashi T, Kimoto S, et al. Sex differences in denture satisfaction. J Dent. 2008 May;36(5):301-8

23. Steele JG, Walls AW, Ayatollahi SM, Murray JJ. Dental attitudes and behaviour among a sample of dentate older adults from three English communities. Br Dent J. 1996 Feb 24;180(4):131-6.

24. MacEntee MI, Walton JN, Glick N. A clinical trial of patient satisfaction and prosthodontic needs with ball and bar attachments for implant-retained complete overdentures: three-year results. J Prosthet Dent. 2005 Jan;93(1):28-37.

25. Strassburger C, Kerschbaum T, Heydecke G. Influence of implant and conventional prostheses on satisfaction and quality of life: a literature review. Part 2: Qualitative analysis and evaluation of the studies. Int J Prosthodont. 2006 Jul-Aug;19(4):339-48.

26. Timmerman R, Stoker GT, Wismeijer D, Oosterveld P, Vermeeren JI, van Waas MA. An eight-year follow-up to a randomized clinical trial of participant satisfaction with three types of mandibular implant-retained overdentures. J Dent Res. 2004 Aug;83(8):630-3.

27. Malo P, Nobre MA, Lopes A, Moss SM, Molina GJ. A longitudinal study of the survival of All-on-4 implants in the mandible with up to 10 years of follow-up. J Am Dent Assoc. 2011 Mar;142(3):310-20.

28. Jacobs R, Manders E, Van Looy C, Lembrechts D, Naert I, van Steenberghe D. Evaluation of speech in patients rehabilitated with various oral implant-supported prostheses. Clin Oral Implants Res. 2001 Apr;12(2):167-73.

29. Ghi H, McGivney P. Influence of tooth proprioception on speech articulation. J Prosthet Dent. 1979 Dec;42(6):609-13.

30. Carlson MDA, Morrison RS. Study design, precision, and validity in observational studies. J Palliat Med. 2009 Jan;12(1):77-82. 